The remarkable fact displayed in his portion of the above table, that locusts only make their appearance in great numbers in the interval from minimum to maximum sun-spot and never during the interval from maximum to minimum sun-spot, is evidently regarded by Dr. Hahn as affording some additional collateral proof in favour of the relation he had already partially established between the rainfalls of Central Europe and the sun'spots, viz., that the interval from minimum to maximum sul-spot is in general drier and warmer than that from maximum to minimum sun-spot. The added dates apparently exhibit a relation to the sun-spot epoch; similar to those given by Dr. Hahn.

Whether the laws which re zulate the visitations of locusts are the same in other parts of the world or not, it is at all events suggestive to notice that the dates of their general appearance throughout the world, given by Mr. Walford in a recent paper to the Statistical Society, entitled, "Famines of the World, Past and Present," exhibit the same relation to the sun-spots as that noted by Dr. Hahn in the case of their visits to Europe.

The date of apparition, the locality visited, and the epoch of sun-spot minimum corresponding, are given below.

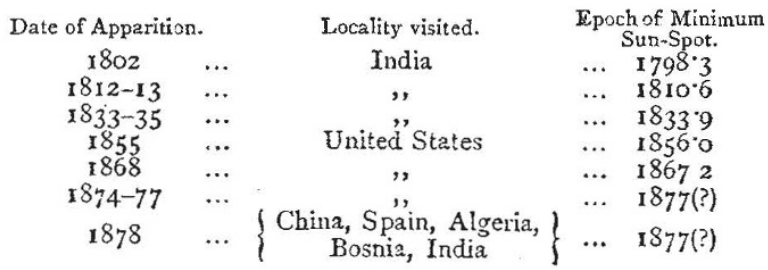

In the face of such an apparent predilection on the part of locusts to swarm during the minimum epoch of sun-spots, it might, $I$ think, be advantageous to institute an extensive com. parison of all past visitations of these insects with the elevenyear cycle of sun-spots. This after due allowance had been made for any known natural cycles of incubation, might possibly bring to light a physical cycle of visitation, the size an 1 position of the area affected by which would, perhaps, afford some indication of the corresponding limits of the rainfall variation.

Ii, Granby Terrace, Glasgow.

E. D. ARChibald

\section{The Range of the Mammoth}

i He criticism by Mr. Clement Reid of my paper recently read before the Geological Society, and not yet published, renders it necessary to remind him that his views as to the manmoth not being pre-glacial are not new, but were advanced by me ten years ago (Pop. Science Review, 1868, p. 275; Geol. Mag., v. 7, July, 1868), and afterwards given up by the light of a wider experience. His arrangement of the complicated glacial deposits of Britain in one linear series, like all similar attempts, appears to me to be based on the fallacy that a difference in the character of the strata, in different areas, implies a difference in point of time. His divisions seem to me purely local, and mostly peculiar to the eastern counties. I see no reas sn for believing that, while five out of the six proposed were being accumulated east of the Pennine chàin, there were no glacial phenomena in the west, in Lancashire or Cheshire, until the last phase, or the sixtb of the eastern divisions; or, in other words, that the lower boulder clay of Lancashire and Cheshire is the equivalent of the last division. On the contrary, the marine sands and gravels covering the lower boulder clays, on both sides of the Pennine chain, and occupying a large area round Crewe, Stafford, and in the Trent Valley, is to me a well-marked horizon, defining the upper from the lower seriez of boulder clays. It is very ilikely that the lower boulder clay of Lancashire and Cheshire is the equivalent of the low'er boulder clay series of Norfolk and Suffolk, as well as of the "moraine profonde" of Scotland. It must, however, be admitted that the correlation of the glacial deposits in various parts of Britain has not yet been satisfactorily made out. " Tot homines quot sententix."

To group them, as they are frequently now grouped, in one linear series, seems to me almost as useless as to construct a history of Europe in which the dynasties ruling various kingdoms at the same time are described one after another, and taken to belong to different periods because they were different dynasties.

W. BOYD DAWKINS

\section{Fossil Floras of the Arctic Regions}

THE author of the valuable paper communicated in NATURE, vol xix. p. 124, on "The Fossil Floras of the Arctic Regions," will find in an essay of mine, entitled "Thalassa," and published in the course of last year, a number of facts and arguments in corroboration of his views regarding the infuence of oceanic currents upon climate. In this essay, which is mainly founded upon the observations made on board H.M.S. Chal. lenger, I have endeavoured to show how a relatively trifling elevation or depression of the sea-coast or of the bed of the ocean may considerably alter the configuration of an oceanic basin ; how such an alteration must affect the direction, volume and temperature of existing currents, and thus have a tendency to change the climate and ultimately the distribution of animal and plant life in the regions bordering on the oceanic basin. I also (p. 29-30) ventured to express the opinion that "it appears hardly necessary to go in search of vast cosmic changes, such as an alteration in the position of the terrestrial axis, a diminution in the a nount of solar heat . . . . while we have, close at hand, an agency whose effect upon climatic condi- $^{-}$ tions may be said to be a matter of daily experience, and which is sufficiently powerful to establish, in almost any region on the earth's surface, the small difference of temperature which is a decree of life or of death to numerous animal and vegetable organism:" To this I may now add, that the influence of oceanic currents upon climate and upon the distribution of life will be most felt and produce the most remarkable results in the Arctic and sub-Arctic regions, which, as we know, may at one period be swept by powerful polar currents, at another invaded by vast masses of warm water brought there by currents from the tropical regions, such, for example, as the Gulf Stream.

The facts brought to light by recent sounding-operations regarding the configuration of the sea-bottom and the distribution of oceanic depths has led me to the conclusion that our continents and oceanic basins, such as they appear at the present day, are of immense antiquity; that changes in the distribution of land and water require for their accomplishment long periods, which, for all we know, may alternate with periods of repose or even of retrocession; and that, consequently, the influence of these changes upon currents and upon climate must be equally slow and uncertain in its duration. If, therefore, the effect of oceanic currents upon climate appears as an important factor, which can no longer be neglected in any discussion on the flora and fauna of past geological epochs, on the other hand, the slow and uncertain progress of the changes above mentioned seems to afford ample scope for the operation of other causes which, besides climate and temperature, determine the existence of certain species in a given area of the earth's surface.

J. J. WILD

\section{The Microphone}

Two subjects of interest in connection with the practical application of the microphone have lately been brought to my notice by Raja Sir T. Madava Row, K.C.S.I., Dewan of Baroda. In the hope of securing a little assistance from some of your scientific readers I hasten to lay them before you.

The first question is with reference to the use of a microphone as a stethoscope. It seems that native Iadies of high position decline altogether to allow a doctor to examine the chest in the ordinary manner. Sooner than submit to such an examination they would prefer to die-certainly rather a staggering fact for those imbued with European ideas. In the cause of humanity it is therefore desirable to do something for those whose position and caste would be imperilled by direct examination. If the microphone could be so delicately arranged as to transmit the auscultatory sounds, a medical ear, even at a distance, would surely be able to detect the existence of any disease of the heart or lungs. In the few experiments that we have made with our limited appliances we have been able to hear the ticking of a watch at a distance of about 200 yards, and the roar of a black ant when attacked by his companion, but as yet we have heard no internal sounds from the human breast. Perhaps with better devised instruments some one may have been able to obtain that which has yet been denied to us. I azo sure many native ladies would be glad to get an affirmative answer to the question, "Can the microphone be used as a stethoscope?"

The second subject seems to me to be a much more difficult one to grapple with. Sir Madava Row writes to me as follows :- 